\title{
Estudos literários e crítica política
}

Benjamin Abdala Junior ${ }^{1}$

\begin{abstract}
This article shows a comparative approach that requires of the critical the consciousness of its enunciative locus (with its hybrid nature), involving analyzes multi / interdisciplinary and political and cultural. The current political moment calls for new strategies of reconfigurations and new pacts. Networks, today, are planetary and involve from the spheres of knowledge clippings to the geopolitical. They constitute a world of multiple borders and the identity issues should be seen in the plural. In this sense, another comparative trend is arising, the call World Litterature. If the postcolonial theory has shown inclinations for zzthe political and social general issues, the definition of so-called locus of enunciation and its historicity is essential for a critical it intends to depart from the generality. So, the university research is very important to mitigate the established hegemony, continuity of asymmetries of cultural flows and also the legitimacy of the hegemonic symbolic power associated with them.
\end{abstract}

Keywords: Comparativism, locus of enunciation, hegemony, asymmetry.

Resumo: Este artigo evidencia uma postura comparatista que exige do critico a consciência do seu locus enunciativo com sua natureza híbrida, envolvendo análises multi/interdisciplin ares e politico-culturais. $\mathrm{O}$ atual momento político solicita reconfigurações de estratégias e repactualizações. As redes, na atualidade, são planetárias, e envolvem desde as esferas dos recortes do conhecimento até às da geopolítica. Configuram um mundo de fronteiras múltiplas e as questões identitárias devem ser vistas no plural. Nesse sentido, surge uma outra tendência comparatista, a da chamada "Literatura Mundo". Se a teorização pós-colonial tem mostrado inclinações genericas para questões politico-sociais, a delimitação do chamado lócus enunciativo e de sua historicidade é imprescindível para uma crítica que pretenda afastar-se da generalidade. É a forma, e a pesquisa universitária tem considerável peso nisso, de se atenuar a hegemonia estabelecida, a continuidade das assimetrias dos fluxos culturais e também a legitimidade do poder simbólico hegemônico a elas associado.

Palavras-chave: Comparativismo, locus enunciativo, hegemonia, assimetria.

\section{Comparações/interações entre sujeitos e o lugar de onde acessamos o mundo}

A primeira consideração que nos parece fundamental na análise comparatista é a necessidade de o crítico ter consciência de seu lócus enunciativo, o lugar de onde ele acessa o mundo. Esse lugar, como todas as formações socioculturais, é de natureza híbrida e envolve análises tanto em termos multi/interdisciplinares, como também em termos políti-

1 Docente dos Cursos de Graduação e Pós-Graduação da USP/CNPQ. 
co-culturais. É importante que tenhamos a consciência de que os campos do conhecimento, estabelecidos pela práxis social em nossa trajetória histórica, constituem escaninhos de ordem prática. Não obstante, em razão da dialética de nosso processo histórico, podem vir a espartilhar os horizontes de seu próprio campo, pois que o conhecimento está sempre em interações/fricções, motivado sobretudo pelas relações interdisciplinares com outras áreas do conhecimento. Vêm justamente dessas interações/fricções a possibilidade que se abre para novas e criativas conformações.

As interações, se inovadoras, pressupõem reciprocidades, quer em relação a esses campos, como também a situações político-sociais. Importa, nesse sentido, que se levem em conta que o pólo de que partimos não pode subordinar ou, se quisermos do ponto de vista político, "colonizar" o outro; ou, em sentido contrário, deixar-se "colonizar" por ele. Se acessamos o mundo através da literatura, isso significa que o modo de conhecimento da realidade para quem se situa nesse campo pode se abrir à política, sociologia, história, linguística etc., para nos ater às esferas das Humanidades, mas também às áreas das chamadas ciências duras, biológicas e da saúde. Não podemos, entretanto, nos deixar colonizar por critérios dessas outras áreas, como muitas vezes ocorre. A atividade crítica deve partir e voltar para o próprio objeto literário que está sendo analisado, que é um modo de conhecimento da realidade afim das ciências humanas e sociais.

Nossa posição, quando buscamos articulações com outras áreas, é colocarmo-nos igualmente como sujeitos do conhecimento. Num outro campo podemos encontrar formas de conhecimento que vêm de experiências históricas que não figuram nos escaninhos de nossa área. Cabe-nos, então, incorporar criticamente essas experiências, revitalizando a nossa práxis, através de reconfigurações em que sejamos igualmente sujeitos e não objetos, reproduzindo especularmente o conhecimento.

Trata-se, pois, de comparar, para com isso afastar práticas rotineiras em torno de mesmices que se estabelecem em nosso campo e, ao mesmo tempo, aberturas para articulações da vida cultural em sentido amplo, abarcando inclusive a cultura material. Observação semelhante vale para o comparatismo entre objetos literários. Uma inclinação, pois, entre sujeitos que se comparam, considerando o sentido das diferenças, sem deixar de considerar o lócus enunciativo de quem compara. Por extensão, o afirmado sobre as interações entre as áreas do conhecimento vale para o comparatismo literário dentro ou fora de fronteiras políticas estabelecidas. A tendência a ser evitada é a deixar-se "colonizar" por parte de quem se reveste de hegemonia em termos de poder simbólico, isto é, das assimetrias dos fluxos culturais. E também em sentido oposto, ao analisarmos narrativas de um povo ágrafo, precisamos considerar o fato de que esse povo possui uma experiência que não temos. Não podemos impor uma metodologia a eles estranha, apenas para procurar legitimar nosso ponto de vista, colocando-os subalternamente nos "devidos" compartimentos administrados por formulações que possam legitimar nossa hegemonia.

Vem dessas postulações, em relação aos países hegemônicos, que administram a hegemonia dos fluxos culturais, a inclinação para não aceitar tais imposições, embora sabendo que eles possuem formas de saberes diferentes dos nossos e que podemos aprender com a experiência deles. É imprescindível, entretanto, considerarmos devidamente, a condição política de sujeitos do conhecimento, matizando essas experiências nas redes do lócus de onde eles falam, que tem sua historicidade e configurações socioculturais, que não deixam de configurar geneticamente o sentido das assimetrias dos fluxos culturais subjacentes.

Nesse sentido, no campo dos estudos comparados das literaturas de língua portuguesa, 
para quem se situa no Brasil, impõe relevar circunstâncias político-culturais que apontamos em Literatura Comparada \& relações comunitárias, hoje2:

$1^{\circ}$ ) o fato de estarmos num momento de crise do modo de pensar a realidade que veio das esferas financeiras, que culminou no crack de 2008, em que foi naturalizada a "imagem utópica do mundo das finanças: desregulamentação e flexibilidade como modelo para a economia, um desenho "naturalmente" extensivo às práticas sociais e culturais. De acordo com a reiterada agenda que vem pautando os meios de comunicação, desregulamentação se afinaria com liberdade e, esta, nas esferas socioeconômicas, com a competitividade, colocada, assim, como critério de eficiência e aspiração maior não apenas das empresas, mas também do indivíduo e da própria democracia. $\mathrm{O}$ individualismo associado à condição da vida democrática, e, mais, como uma das inclinações fundamentais do humanismo"3;

$2^{\circ}$ ) relacionado a essa situação, temos de levar em consideração que o "atual momento político solicita, no âmbito do Brasil e da comunidade mundial, reconfigurações de estratégias e repactualizações, o que já vêm ocorrendo nas relações internacionais. No plano da vida cultural, em nosso país, a compreensão do sentido dessa repactualização ainda é muito ligeira, desconsiderando as esferas culturais. Nossa intelectualidade, em geral, temse colocado a reboque dos acontecimentos, com discursos legitimadores das hegemonias, voltando-se mais para a administração da diferença nas balizas do sistema estabelecido. E diante das novas solicitações é de se entender que essas vozes da intelectualidade, muitas vezes melancólicas e contemplando ruínas, devem assumir atitudes mais ativas e prospectivas, para criar ou redesenhar, com matização mais forte, tendências de cooperação e solidariedade, que sempre embalaram ideais democráticos. Pelas margens do sistema das assimetrias hegemônicas, abre-se a possibilidade real de se estabelecer efetivos contrapontos ao paroxismo da competitividade, que envolve e se coloca como paradigma da vida econômica, social e cultural, de acordo, com a lógica dessas assimetrias dos fluxos econômicos e culturais"";

$3^{\circ}$ ) essa inclinação para a "regulação da vida social já se manifestava, na situação anterior ao crack, justamente como reação aos efeitos perversos dos modelos articulatórios do capital financeiro, que flexibilizaram fronteiras nacionais para impor as assimetrias de sua ordem hegemônica. Foi pelas brechas desse sistema - já que toda hegemonia é porosa - que se firmou a necessidade de conexões amplas, abrindo a possibilidade de articulações comunitárias de sentido supranacional. Nesta nova situação, essas associações comunitárias tornam-se ainda mais urgentes, e envolvem a possibilidade de novas articulações, amplas e estruturadas em múltiplos níveis, desde a vida econômica às esferas da vida sociocultural"'.

$4^{\circ}$ ) entre os comunitarismos supranacionais é politicamente relevante que desenvolvamos laçadas de cooperação e solidariedade com os países de língua portuguesa e espanhola, enlaçando a iberoafroamérica. Mais particularmente, devemos considerar que "inclinações comunitárias linguístico-culturais sempre embalaram as tendências democráticas, nos países de língua portuguesa. A situação atual é evidentemente diferente do que acontecia no período colonial e também no estabelecimento e consolidação de nossos sistemas republicanos, como o próprio conceito de fronteiras. O comunitarismo afirma-se, na atualidade, envolvendo pluralidade nas articulações políticas, pautadas sempre pela supranacionalidade. Relevantes são as ações políticas na forma de blocos, com linhas de ação amplas, da vida

2 Cotia: Ateliê Editorial, 2012. 327 p.

3 Op. cit., p. 9.

4 Op. Cit., p. 10.

5 Op. cit., p. 10-11. 
econômica à cultural. Blocos politicamente mais eficazes para estabelecer contrapontos às assimetrias dos fluxos hegemônicos supranacionais do novo imperialismo, e também em suas correspondências nacionais e/ou, mesmo, estratificações sociais"\%;

$5^{\circ}$ ) impõem-se, pois, mudanças de atitudes também em termos de comparatismo literário. Não podemos nos limitar à análise das redes estabelecidas entre as esferas do conhecimento, mas que problematizemos os fatores que lhes são subjacentes e que geraram sistemas de hierarquização em suas articulações econômicas e socioculturais. Como indicou Lucien Goldmann em seu "Balanço Teórico" (em cores talvez excessivamente fortes e que devem ser em parte mediatizadas), é necessária a busca dessas bases para que a crítica se afaste "de qualquer posição moralizante como, por exemplo, a da Escola de Frankfurt e, em especial a de Herbert Marcuse. Para esses pensadores, que criticam e condenam a sociedade contemporânea sem perguntar em que medida essa crítica é baseada numa força social interna a essa sociedade, as únicas perspectivas tornam-se o isolamento do pensador no mundo de seus pares, ou a ditadura provisória e temporária dos filósofos que deveriam transformar a sociedade"

Diríamos, nessa perspectiva, como afirmamos em nossa tese de livre-docência na

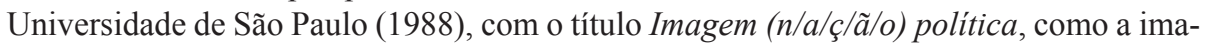
ginação política, pela ação de escritores, pode reconstruir cacos da nação, advindos das assimetrias dos fluxos culturais (hegemonias evidentemente que não se limitam apenas ao colonialismo). A versão em livro foi publicada um ano depois, com o título Literatura, história e política ${ }^{8}$ Essa imaginação política é fundamental também para a atividade critica, pois remove os muros da especialização meramente acadêmica, que a circunscreve apenas à chamada "produtividade", como numa esteira industrial, ou mesmo ao estabelecimento de laços de solidariedade restritos aos atores dessa área do conhecimento. $\mathrm{Na}$ verdade, o campo meramente acadêmico acaba assim por ser administrado, levando-o a pairar como nuvens distantes da vida social, como pode ocorrer inclusive com a própria imaginação sociológica que por ali acaba por circular apenas entre pares. Para além dos escaninhos do ensimesmamento desse campo intelectual ${ }^{9}$, importa que sejam configuradas articulações contextuais mais amplas e problemáticas pela diversidade das esferas econômicas, sociais e culturais envolvidas, que levem esse campo de produção do conhecimento a interagir com as esferas públicas, de sentido político.

\section{Cooperação/solidariedade e o princípio de juventude}

Neste momento de repactualização internacional, por oposição ao império do mercado, são relevadas formas de cooperação à escala planetária. São enfatizados, pela hegemonia que busca legitimidade e também por aqueles que se colocam contra essa hegemonia, ideais de respeito às diferenças de toda ordem e à democracia. Não obstante, as inclinações comunitárias, a contrapelo da hegemonia que pretende administrar a diferença, emergem

6 Op. Cit., p. 11.

7 Löwy, M. e Naïr, S. Lucien Goldmann ou a dialética da totalidade. São Paulo: Boitempo Editorial, 2008. p. 153.

8 ed. Cotia: Ateliê Editorial, 2007. p. 278-279.

9 O conceito de campo intelectual e, mais especificamente, literário, foi cunhado por Pierre Bourdieu em 1992 (Edição brasileira: As regras da arte: gênese e estrutura do campo literário. São Paulo: Companhia das Letras, 1996). Trata-se de uma estrutura complexa que vai da economia à cultura em sentido amplo, envolvendo relações entre escritores e seus leitores, editores, críticos etc. Isto é, articulações múltiplas em que o autor e suas produções mostram-se imbricados com a vida social. 
para primeiro plano, como forma de mediação entre os múltiplos campos da vida social e do estado. Diante dos novos desafios de ênfase no comunitarismo, particularizando nosso campo de trabalho, parecem-nos importantes que os estudos de literatura comparada, sejam vistos numa dimensão política e sociocultural. Sabemos que veio de nosso processo histórico as assimetrias de poder simbólico afeitas ao processo de colonização e, depois, da permanência dos hábitos de colonizados, comutando centros hegemônicos. Verificar essas bases da circulação cultural, com viés crítico e sem assimilacionismos, pode ser uma forma de nos situar diante dos fluxos inclinados à continuidade dessa colonização de nosso imaginário.

Nas atitudes de atores culturais do passado, podem ser configuradas, assim, linhas que são imprescindíveis para a melhor compreensão de nossa atualidade sociocultural. Entretanto, a restrição às assimetrias desse comparatismo, mesmo se nos pautarmos pela criticidade, não é suficiente. Temos proposto outra forma de comparatismo. Um comparatismo prospectivo, pautado por relações comunitárias, um comparatismo da solidariedade, da cooperação. Comparar diante de problemáticas que nos envolvem a todos para nos conhecer naquilo que temos de próprio e em comum. Enlaces comparatistas em que as particularizações do passado devem ser reconfiguradas em termos prospectivos e tendentes a ações de reciprocidade. Não mais a histórica relação sujeito/objeto, mas agora de sujeito/ sujeito, que se comparam em aproximações e fricções, tendo em conta desafios que se colocam em termos da atualidade sociocultural.

Neste momento de crise e de repactualizações políticas, tornam-se importantes atitudes pautadas por otimismo crítico. Acreditar que o mundo possa ser diferente e melhor do que ele é. Para além da necessária inclinação da negatividade inerente ao pensamento crítico, a motivação e o embalo de um princípio de juventude, consubstanciado em projetos e ações político-culturais mais amplos.

Se é próprio da melhor literatura se voltar para aquilo que falta, há, pois, que renovar atitudes no âmbito da crítica literária, em sentido prospectivo, para nos valer ainda de um paralelismo com os anos de 1930, descartando agora o enredo de ambiência melancólica, que veio das frustrações que marcaram a Modernidade. Uma nova atitude implica ter a esperança como princípio ${ }^{10}$. Ao contrário da ideologia do fim da história e da inculcação de que vivemos no melhor dos mundos, é imprescindível acreditar em nossa potencialidade subjetiva e objetivá-la em projetos inclinados para o futuro. Como explicita o poeta Carlos de Oliveira,

"Na poesia,/ natureza variável/ das palavras,/ nada se perde/ ou cria,/ tudo se transforma:/ cada poema, no seu perfil/ incerto/ e caligráfico,/ já sonha/ outra forma. ${ }^{11}$ "

Para quem se situa no Brasil, no âmbito da cultura, o momento é de relevar blocos de nossa comunidade linguístico-cultural, de forma correlata às estratégias de ordem econômica que vêm sendo desenvolvidas pelo país. Mais particularmente, importa estreitar relações com nosso bloco linguístico-cultural e também, numa laçada mais ampla, com os países iberoamericanos. As redes, na atualidade, são mais amplas, planetárias, e envolvem desde as esferas dos recortes do conhecimento até às da geopolítica. Configuram um mundo de fronteiras múltiplas e as questões identitárias devem ser vistas no plural ${ }^{12}$. Outras articulações supranacionais se configuram, ao lado daquelas que vieram de nossa

10 Cf. Bloch, Ernst. O principio esperança. 3 volumes. Rio de Janeiro: Eduerj/Contraponto, 2005/2006.

11 "Lavoisier". Obras de Carlos de Oliveira. Lisboa: Editorial Caminho, 1992. p. 223.

12 Cf. Abdala Junior, Benjamin. Fronteiras múltiplas, identidades plurais. São Paulo: Editora SENAC São Paulo, 2002. 


\section{Conexão Letras}

formação histórica, como ocorrem igualmente nas relações econômicas. O comunitarismo linguístico-cultural constitui um ponto de partida político e estabelece, para nós, um "nó", em termos de redes comunicacionais, de onde abrimos "janelas" igualmente múltiplas. Pelo comunitarismo cultural, podemos mostrar rostos diferenciados, em diálogo com outros. Num mundo em que o inglês tornou-se uma espécie de língua franca, é importante que também falemos em português como língua de cultura, numa associação mais particularizada com a língua espanhola.

Ter esperança ou pautarmo-nos pelo princípio de juventude implica a atualização de gestos prospectivos, tal como ocorreu no passado com a literatura social do período entre-guerras, voltando-nos aos anos de 1930, e que se projetou pelos anos da guerra-fria. A grande diferença de situação, quando se compara os dois cracks financeiros, é que em 1929 a intelectualidade acreditava que as coisas poderiam ser diferentes e agora essa manifestação do desejo se mostra mitigada, envolvida pelos modelos articulatórios da utopia do mundo desenhado pelo capitalismo financeiro. De acordo com esses modelos, viveríamos no melhor dos mundos - um eterno presente, da produção e competição. Mais do que a força das idéias e da reflexão, continuam dominantes sistemas de modelizações do pensamento e de condutas afinados com um individualismo narcisista reverenciado pela mídia, que só destaca quem se coloca nas passarelas daquela que já foi chamada sociedade do espetáculo.

\section{Marcas eurocêntricas e a sobrevivência das formas}

Estamos longe, nos estudos comparatistas, das tendências eurocêntricas positivistas dos estudos das "fontes", mas os cânones continuam a vir dos países hegemônicos da Europa Ocidental e suas extensões norte-americanas. São as literaturas "maiores" e as outras, ao sul da Europa e próprias do mundo colonizado, as "menores". Em literatura comparada, esse primeiro modelo de estudo correspondeu à hegemonia teórica francesa, substituída pela norte-americana em meados do século XX, onde os recortes nacionais foram vistos em suas interações supranacionais. Como indica Cláudio Guillén, afirma-se, então, o momento da supranacionalidade, para além das fronteiras nacionais ${ }^{13}$. Desloca-se a hegemonia, em termos de literatura comparada, para a outra margem do Atlântico Norte.

As hegemonias nunca são absolutas, mas porosas. Se nessas teorizações da década de 50 aparecem formalismos e desconsiderações político-sociais, surgirão, nas décadas finais do século, novas perspectivas para os estudos comparados, imbuídos de sentidos políticos, presentes, por exemplo, nas obras de Fredrick Jameson ${ }^{14}$ e de Edward W. Said. São as contradições dentro do mesmo sistema, que envolvem a imagem de vida democrática, um princípio de legitimidade de quem se vale das assimetrias dos fluxos culturais e que não deixa de estar presente nos discursos oficiais norte-americanos.

$\mathrm{Na}$ atualidade e em decorrência desse comparatismo Leste/Oeste em que foram importantes teóricos que se deslocaram para os centros hegemônicos, surge uma outra tendência comparatista, a da chamada "Literatura Mundo". Do ponto de vista político, consideramos necessário, como estamos argumentando, a consideração de laçadas comunitárias, por sobre a porosidade das hegemonias estabelecidas. A articulação comunitária configura formas de poder simbólico contra uma pastichização que interessa apenas para as configurações hegemônicas.

13 Introducción a La literatura comparada (Ayer y hoy). Barcelona: Tusquets Editores, 2005.

14 Marxismo e forma: teorias dialéticas da literatura no século XX. Trad.: Simon, I.; Xavier, I. e Oliboni, F. São Paulo: Editora HUCITEC, 1985. 
Edward W. Said desenvolveu a tese, na perspectiva de sua crítica política, de que a cultura integra a ação colonizadora, um espaço de tensões/conflitos. O próprio conceito de Oriente foi cunhado para justificar o domínio imperial sobre os "outros", sempre inferiores ${ }^{15}$. Um desenho análogo ao dos povos africanos, para justificar sua escravidão pelos "civilizados" colonialistas. Para Said, a análise dessas tensões entre o império e as colônias envolve tratar cultura e imperialismo numa relação de interdependência. E é com esse horizonte, que é importante estudar a forma mentis desse processo. Em termos de intersubjetividade, o desenho que envolve relações de dominação, no plano interno dos blocos hegemônicos e das regiões subalternas, corresponde aos gestos coloniais, que continuam a marcar a vida subjetiva e cultural desses povos, seus universos simbólicos.

Foi assim que desde os tempos coloniais o eurocentrismo procurou estabelecer a inteligibilidade e, principalmente, a legitimidade necessárias às práticas de dominação, justamente porque inferiorizavam, tanto em discursos científicos quanto leigos, os espaços, povos e culturas das colônias e apontavam a sua necessidade de evolução em amplos sentidos. Hoje, essa inclinação persiste nos olhares, práticas e representações que permitem a continuidade da dominação e manutenção de determinadas hegemonias e hierarquizações, mesmo que de forma sutil, ininteligível, naturalizada ou compartilhada por todos. Um amplo sistema de modelização de pensamento e de conduta, em dimensão planetária. Não podemos nos esquecer de que na Europa e nos EUA há numerosas comunidades marginalizadas, como os irlandeses, ciganos, negros, latino-americanos, judeus, muçulmanos, os habitantes das periferias, gays, lésbicas etc. Foi nesse contexto situacional híbrido e de fricções que apareceram as obras de Fredrick Jameson, Edward W. Said, Homi K. Bhabha ${ }^{16}$ e Stuart Hall $^{17}$, entre outros.

O eurocentrismo - como se vê - corresponde hoje à ocidentalização, que não tem precisão geográfica, mas tem suas bases políticas e econômicas. Envolve toda uma série de repertórios secularmente acumulados, de onde vêm as reflexões e práticas espalhadas pelo mundo, através das assimetrias dos fluxos culturais. Evidentemente, convém repetir, aprendemos com a experiência do outro. Afinal, somos todos misturados. As identidades são sempre plurais, já indicamos. Não obstante, uma certa hibridização que conflui para uma espécie de plasticização indefinidora de fronteiras, que, na verdade, são configuradas e múltiplas, pode ser estratégia similar à da mestiçagem das elites brasileiras: mesclagens tendentes a formulações eurocêntricas.

Preferimos considerar que as fronteiras são múltiplas e não líquidas, indefinidas. Se existe a tendência à fragmentação posmoderna, afim do modo de administrar e pensar o mundo pelo viés das finanças, podemos situar as fronteiras de acordo com processos de articulações que se alternam, sobrepõem e se imbricam, mas que não se liquefazem, de acordo com a teorização de Zygmunt Bauman ${ }^{18}$ Somos igualmente múltiplos do ponto de vista identitário e, na verdade, uma visão crítica das implicações políticas desses caracteres (nível individual, nacional, social), verificará que eles se atritam e não deixam de estabelecer hegemonias ou dominâncias, que podem ser reversíveis.

Assim são os hábitos ${ }^{19}$, que em suas linhas articulatórias impregnam os atores sociais,

15 Cf. Orientalismo: o Oriente como invenção do Ocidente. Trad.: Tomás Rosa Bueno. São Paulo: Companhia das Letras, 1990.

16 O local da cultura. Trad.: M. Ávila, E. L. L. Reis, G. R. Gonçalves. Belo Horizonte: UFMG, 1998.

17 Da diáspora: identidades e mediações culturais. Org: Liv Sovik. Belo Horizonte-Brasília: Editora UFMG/ UNESCO, 2003.

18 Tempos líquidos. Trad.: Carlos Alberto Medeiros. Rio de Janeiro: Jorge Zahar Editor, 2006.

19 Associamos o conceito de habitus, de Pierre Bourdieu, ao de modelo de articulação que vem da práxis (o 


\section{Conexão Letras}

mesmo em situações políticas que poderiam contraditá-los. Observe-se, nesse sentido, o romance Mayombe, de Pepetela, escrito em plena guerrilha das lutas de libertação nacional de Angola. O sentido crítico do narrador destaca linhas de articulação de hábitos, que impregnam suas personagens, deixando à mostra as reais motivações dos guerrilheiros, mitificados pelos discursos oficiais. Citemos uma personagem feminina, que de um ângulo periférico analisa a situação que experimenta:

"Isso é que me enraivece. Queremos transformar o mundo e somos incapazes de nos transformar a nós próprios. Queremos ser livres, fazer a nossa vontade, e a todo momento arranjamos desculpas para reprimir nossos desejos. E o pior é que nos convencemos com as nossas próprias desculpas, deixamos de ser lúcidos. Só covardia. É medo de nos enfrentarmos, é um medo que nos ficou dos tempos em que temíamos a Deus, ou o pai ou o professor, é sempre o mesmo agente repressivo. Somos uns alienados. O escravo era totalmente alienado. Nós somos piores, porque nos alienamos a nós próprios. Há correntes que já se quebraram mas continuamos a transportá-las conosco, por medo de as deitarmos fora e depois nos sentirmos nus." ${ }^{20}$

Vieram de nossa formação hábitos alienados e as formas culturais, tal como as formas políticas, sociais e econômicas, resistem. Há nelas, de um lado, uma experiência acumulada; e, de outro, implicações ideológicas que tendem a justificar hegemonias. Constituem desenhos ou linhas que resistem e determinam a formação de caracteres, com papéis sociais marcados. O grande problema, do ponto de vista político, é que tais impregnações fazem parte do cotidiano e configuram as expectativas de cada ator, dirigente ou dirigido. Tais gestos alienantes serão mais enfáticos na obra posterior, de Pepetela, quando ironizará a nova sociedade urbana de Angola.

Nos EUA, houve um transplante mais efetivo da população européia e o estabelecimento de um estado dos "brancos", originalmente puritanos, que se recusaram à mistura. Consequência: extermínio dos ameríndios e o apartheid dos ex-escravos. Só a partir da segunda metade do século XX, essas populações das margens começaram a fazer valer seus direitos de cidadania. E ganharam peso político-social e cultural, mais recentemente, pela presença ativa da grande população de migrantes, que vieram de outras margens. A discussão sobre a mestiçagem, escamoteada pelas elites norte-americanas, ganhou então as universidades e já é matéria de sua indústria cultural, tendo em vista a busca de legitimidade para a preservação da hegemonia desse país.

\section{Experiência histórica e fronteiras culturais}

O processo colonial fixou hábitos, repertórios literários e culturais, que vieram dessa experiência histórica e dos contatos culturais entre povos que até então não se conheciam. Se há hoje toda uma inclinação crítica para mudanças de paradigmas, sejam eles filosóficos, estéticos, em relação às áreas do conhecimento, entendemos que essa tendência não pode se naturalizar sobre um rótulo genérico de um "pós", uma redução ao obsoleto de toda

homem com ser ontocriativo). Para Bourdieu o "habitus, como indica a palavra, é um conhecimento adquirido e também um haver, um capital (de um sujeito transcendental da tradição idealista) o habitus, a hexis, indica a disposição incorporada, quase postural -, mas sim o de um agente em acção: tratava-se de chamar a atenção para o 'primado da razão prática' de que falava Fichte, retornando ao idealismo, como Marx sugeria nas Teses sobre Feuerbach, o 'lado activo' do conhecimento prático que a tradição materialista, sobretudo com a teoria do reflexo, tinha abandonado (O poder simbólico. Trad.: Fernando Tomaz. Lisboa: Difel / Rio de Janeiro: Bertrand, 1989. p. 61.

20 São Paulo: Ática, 1982. p. 208. 
uma experiência que se consubstancia no presente. Pior ainda pode ocorrer em relação às instâncias políticas, onde o "pós", afeito às condições da mídia e dos produtos moda, procura tudo reduzir a uma tabula rasa, sem passado. A experiência histórica e suas realizações passam a ser situadas como um repertório passivo, para a estilização sem história, formas restritas a uma espécie de repertório passivo, desconsiderando-se o processo que as modelizou.

Temos de levar na devida consideração o fato de que a teorização pós-colonial tem discutido convenientemente questões relativas à mundialização econômica, com implicações socioculturais, aos deslocamentos dos povos e ao processo de americanização do mundo, sob o impacto da mídia e do consumo mercadológico. Em relação às questões político-sociais, entretanto, ela pode tender a inclinações genéricas. São igualmente póscoloniais quaisquer sociedades marcadas pelo colonialismo, sem maior consideração sobre sua historicidade, nivelando países que se emanciparam no período pós-Segunda Guerra Mundial, aos que se emanciparam desde o século XIX. Falar de pós-colonialismo, sem consciência dessas especificidades, implica nivelar uma cultura como a do Canadá, ou da África do Sul, por exemplo, à complexa situação cultural da Índia - ambas ex-colônias britânicas. Só uma análise das redes políticas, econômicas e socioculturais pode revelar de que pós-colonialianidade se trata. Essa situação se torna ainda mais complexa, se vinculada - como acontece - à ênfase ao nomadismo diaspórico dos estudos pós-coloniais. Coloca-se novamente a necessidade de se considerar de onde fala o crítico e os laços socioculturais que acabam por enredar suas formulações discursivas.

São muitos os pós-colonialismos. Há, por exemplo, o pós-colonialismo do ex-colonizador, que encontramos num romance como Os cus de judas, de Lobo Antunes ${ }^{21}$; e, para contrastar, o do ex-colonizado, como em Mayombe, de Pepetela ${ }^{22}$. O primeiro vai desconstruir mitos e fazer de sua memória individual um depoimento que se quer história. Pepetela, numa direção oposta, embala-se por mitos, sem deixar de criticar indivíduos que se querem mitos. Nessa crítica, evidencia posturas etnocêntricas do passado que se reproduzem no presente. Em Lobo Antunes, enfatiza-se a desconstrução dos mitos e a distopia; em Pepetela, na formação de um novo estado nacional, a construção e a utopia. Há ainda o pós-colonialismo dos colonizadores que permaneceram na metrópole e dos ex-colonizados que migraram. A clara delimitação do chamado lócus enunciativo e de sua historicidade é, pois, imprescindível para uma crítica que pretenda afastar-se da generalidade.

Refletir sobre especificidades nacionais implica situá-las num processo de agenciamentos comunitários que tem um solo histórico e relações de poder simbólico. Temos destacado o sentido político de se discutir literatura no âmbito do comunitarismo iberoafroamericano, mas - voltamos a insistir - as articulações comunitárias podem ser de muitas ordens e politicamente nos parece importante relevar que o mundo atual é de fronteiras múltiplas e identidades plurais, seja numa perspectiva individual ou nacional. São interações que levam à consideração de um complexo cultural híbrido, interativo, onde a cultura brasileira, por exemplo, é multifacética e se alimenta produtivamente de pedaços de muitas culturas, sem deixar de sofrer os efeitos das assimetrias dos fluxos culturais.

Tais considerações, para além das especificidades nacionais, torna necessária a consideração do repertório enfaticamente híbrido de nossa formação cultural. Na apropriação desse repertório, a consciência dessa historicidade e relações de poder que ensejou, pode contribuir para o afastamento de produções miméticas, afins da convenção ou do estereótipo.

21 Os cus de judas. Lisboa, Editorial Vega, 1979.

22 São Paulo: Ed. Ática, 1982. 


\section{Conexão Letras}

Tal sentido crítico contribui para o desenvolvimento de inclinações abertas à criatividade e que às vezes acabam para o questionamento de espartilhos ideológicos e identidades míticas.

Em Literatura, história e política, analisamos a circulação cultural entre o Brasil, Portugal e África, tendo como motivo condutor a imagem de Pasárgada, de Manuel Bandeira. Procuramos então discutir essa figuração utópica por recorrência a Osvaldo Alcântara (pseudônimo poético de Baltasar Lopes) e a Ovídio Martins. O primeiro, com os "pés" em Cabo Verde, sonha à Bandeira com uma pasárgada que existiria em outra margem do oceano. Se o poeta brasileiro imagina um reino com um rei bonachão que lhe permitiria todas as "libertinagens" (título da coletânea do poeta brasileiro), Osvaldo Alcântara tem saudade de uma pasárgada futura que encontraria no "caminho de Viseu" (... indo eu, indo eu, /a caminho de Viseu ${ }^{23}$. Osvaldo Alcântara, repetimos, estava com os pés em Cabo Verde, mas a cabeça inclina-se para fora, para as possibilidades de se encontrar plenitude na imigração. Sua perspectiva é aquela que historicamente sempre se colocou para seu povo de migrantes e ele não deixa de ter consciência de que esta saudade fina de Pasárgadalé um veneno gostoso dentro do meu coração ${ }^{24}$. A partir das carências de sua terra, Osvaldo Alcântara sonha com o que não tinha.

A identificação no repertório comum não implica, assim, mimetismo. A distância crítica advém não apenas através da perspectiva de um brasileiro, mas sobretudo de quem estabelece suas bases poéticas na persistência de uma mesma linguagem comunitária. Ampliando essas observações, podemos afirmar que são importantes do ponto de vista crítico estudar esses diálogos, embutidos - explicitamente ou não - nos repertórios literários, que circulam entre os países de língua portuguesa. Por outro lado, relevar as relações de poder que envolvem essa circulação é uma forma de se afastar da celebração, seja da mimese ou de um pretenso sincretismo ou do hibridismo, que desconsidera as relações de poder e encaminha atitudes assimilacionistas tendentes à cultura do colonizador e suas implicações no que tange à cooptação política. Não se pode, entretanto, deixar de considerar devidamente o fato de que a plasticidade da língua literária portuguesa vem desde sua formação nos tempos medievais e só pode ser estudada adequadamente na dinâmica das tendências dos campos intelectuais supranacionais, nos processos de mundialização das culturas européias.

\section{A administração da diferença}

À flexibilidade da circulação dos produtos culturais, ao ritmo nômade do capital financeiro, que se articula em rede, sempre reduzindo distâncias por velocidade, sempre desdobrável, parece-nos importante contrapor estratégicas contra-hegemônicas, associadas aos comunitarismos supranacionais. Esse processo vertiginoso de estandardização dos produtos culturais, por parte da economia de mercado, não se restringe à estandardização de massa. Convém não nos esquecermos de que a hegemonia possui bases amplas, que não deixam de ser mercadológicas, e procura incorporar em suas redes mesmo a contestação de seu próprio sistema. Trata-se da perspectiva da administração da diferença, que temos insistido em apontar. A diferença como administração política e abertura de nicho de mercado. Noutro sentido, esta incorporação pode contribuir para a dinamização do sistema: mudar para que as coisas continuem estruturalmente as mesmas. Ou, como aparece no livro/ filme O leopardo, de Giuseppe Lampedusa/Luchino Visconti, na fala de Tancredi, príncipe

23 ABDALA Junior, Benjamin. 2. ed. Literatura, história e política. Cotia: Ateliê Ed., 2007. p. 81.

24 Idem. Ibidem. p. 81. 
de Falconeri, na Sicília: "É preciso que algumas coisas mudem, para que tudo continue na mesma". A emergência parcial do novo, sob controle político-social das estruturas pré -estabelecidas e que faz valer sua hegemonia para controlá-lo, ao mesmo tempo em que se beneficia de sues influxos para atualizar suas redes numa nova configuração histórica.

Neste momento que se afigura em processo pós-neoliberal, a afirmação de uma tendência mais tolerante, que procura valer-se da estratégia de administrar da diferença, afim, por exemplo, do multiculturalismo de matização liberal, pode constituir uma maneira mais inteligente e de longo prazo de se preservar e mesmo promover a hegemonia. Estratégia para um capitalismo administrado, um retorno, em nossas bases, dos princípios norteadores do governo Roosevelt. Seria uma espécie de um novo New Deal, de onde - já que as coisas são misturadas - foi possível surgir, não obstante, a obra de um Caldwell, Hemingway, Dos Passos, Gold, Steinbeck, Faulkner etc. E também a organização das Nações Unidas e da carta que estabelecia o princípio da autodeterminação dos povos.

Tal eurocentrismo de matização norte-americana pode vir a ser agora atenuado, na nova configuração que se esboça, como uma das tendências possíveis da política imperial. Fala-se insistentemente na necessidade de "tolerância": tolerância liberal, uma nova modalidade dos pressupostos de caridade, uma via de mão única, sem reciprocidade. A aproximação dos excluídos, que foi uma das bases fortes da eleição do presidente Barack Obama e que fez a diferença, não é evidentemente relevada. Para além dessa modulação da tolerância, é imprescindível ao pensamento crítico descortinar também as relações de poder envolvidas. Sem a discussão dessas relações, o discurso multicultural que, ao que parece, deve se afirmar ainda mais, não deixará de ser um veículo conceitual de administração da diferença, tendo em vista a manutenção da hegemonia norte-americana, vale dizer, de suas elites. Falta a esse multiculturalismo de tintas liberais a consideração de vozes simultâneas em tensão, uma espécie de um áspero concerto polifônico construído pelas diferenças. Logo, uma perspectiva crítica capaz de contraditar formulações discursivas hegemônicas, tendentes ao nivelamento de uma espécie de "branqueamento" eurocêntrico, uma forma mentis análoga à que se produziu nas elites brasileiras, desde o século XIX.

Reiteramos, pois, no contraponto ao que naturalizou até o momento do crack econômico de 2008, de que o acesso à rede supranacional se faz num lócus enunciativo determinado e ele é fundamental para a crítica. Se na vida universitária, por exemplo, um docente situa-se numa universidade norte-americana, ele não pode desconsiderar o fato de que seu discurso pode estar associado a estratégias hegemônicas desse país. Estas são considerações relativas a uma hegemonia que procura legitimar-se nas esferas intelectuais e públicas, em que a sociedade civil se articula com as esferas de estado, formando um consenso supranacional. Junto com tais estratégias que procuram legitimar assimetrias, em que a ação da mídia é igualmente importante, há evidentemente formas de dominação despótica que operam desde o campo econômico ao militar, mais ou menos atuantes, conforme as oscilações das relações políticas, estabelecidas sobretudo por motivações econômicas.

Em termos de consenso hegemônico, na atualidade, ele se efetua não apenas no sentido da aceitação, mas sobretudo de promover a capitalização da diferença. Uma diferença que se consubstancia em produtos, desde o da imagem democrática do país hegemônico até a mercadorias mais explicitamente comercializáveis.

Para ilustrar a abrangência do processo de mercantilização que atinge inclusive a identidade individual, podemos nos valer de um poema de Carlos Drummond de Andrade, "Eu Etiqueta" (Corpo, 1984). As mercadorias aí já não apenas espreitam, mas introjetam-se em todas as pessoas, inclusive e de forma irônica, no próprio poeta. As pessoas perdem suas identidades, transformadas numa espécie de vitrine de mercadorias. E as marcas consumidas 
(etiquetas) valem menos pelo valor de uso e, mais, pelo status que conferem. Um consumo acrítico que, no processo de simbolização literária, não deixa de se associar a hábitos que vêm desde os tempos coloniais, como o autoritarismo denunciado em A rosa do povo (1945), do mesmo poeta. Etiquetas, quase sempre produtos, marcas ou modelos importados situados como superiores. E talvez pudéssemos acrescentar, já que a simbolização poética o permite: esse mesmo gesto é correlato a hábitos que perduram no campo científico ou na crítica literária - a importação sem sentido crítico. Uma citação nos estudos literários não poderia ter a função de uma etiqueta? Uma etiqueta a ser observada pelo olhar irônico, pretensamente menor do poeta, que se vê como "homem-anúncio itinerante, / Escravo da matéria anunciada. / Estou, estou na moda. / É doce andar na moda, ainda que a moda / Seja negar minha identidade (...)"25.

Em relação a essas práticas que oscilam entre a hegemonia que procura se legitimar e o despotismo de quem tem o poder, não se pode esquecer a posição dos Estados Unidos como único país a defender a inserção da cultura como "produto", na Organização Mundial do Comércio. Para além do produto diretamente comercializável, a hegemonia implica um "reconhecimento" internacional da instituição onde esse crítico trabalha, o que certamente atrairá alunos e docentes, inclusive dos países não-hegemônicos. A partir dessa situação, serão criadas condições para convênios interinstitucionais com esses países, tendentes à preservação da hegemonia estabelecida. Só uma efetiva reciprocidade entre os atores da comunidade universitária envolvida poderá atenuar essas assimetrias. Isto é, a consciência da dimensão política que envolve a pesquisa científica. A busca da "eficácia", aparentemente neutra, mas no fundo mimética e sem criticidade, pode mascarar processos que respaldam a continuidade das assimetrias dos fluxos culturais e também da legitimidade do poder simbólico hegemônico a elas associado.

\section{Referências}

ABDALA JUNIOR, Benjamin. Fronteiras múltiplas, identidades plurais: um ensaio sobre mestiçagem e hibridismo cultural. São Paulo: Editora SENAC São Paulo, 2002. . 2. ed. Literatura, história e política. Cotia: Ateliê Ed., 2007. 2012. . Literatura Comparada e relações comunitárias, hoje. Cotia: Ateliê Editorial,

ANDRADE, Carlos Drummond. Corpo. Rio de Janeiro: Record, 1984.

BAUMAN, Zygmunt. Tempos líquidos. Trad.: Carlos Alberto Medeiros. Rio de Janeiro: Jorge Zahar Editor, 2006.

BHABHA, Homi K. O local da cultura. Trad.: M. Ávila, E. L. L. Reis, G. R. Gonçalves. Belo Horizonte: UFMG, 1998.

BLOCH, Ernst. O princípio esperança. 3 vols. Trad.: Nélio Schneider. Rio de Janeiro: EdUERJ/Contraponto, 2005/2006.

BOURDIEU, Pierre. O poder simbólico. Trad.: Fernando Tomaz. Lisboa: Difel / Rio de Janeiro: Bertrand, 1989.

. As regras da arte: gênese e estrutura do campo literário. São Paulo: Companhia das Letras, 1996.

GUILLÉN, Claudio. Introducción a La literatura comparada (Ayer y hoy). Barcelona: Tusquets Editores, 2005.

25 ANDRADE, Carlos Drummond. Corpo. Rio de Janeiro: Record, 1984. 
HALL, Stuart. Da diáspora: identidades e mediações culturais. Org: Liv Sovik. Belo Horizonte-Brasília: Editora UFMG/UNESCO, 2003.

JAMESON, Fredric. Marxismo e forma: teorias dialéticas da literatura no século XX. Trad.: Simon, I.; Xavier, I. e Oliboni, F. São Paulo: Editora HUCITEC, 1985.

LOBO ANTUNES, António. Os cus de judas. Lisboa: Editorial Vega, 1979.

LÖWY, M. e NAÏR, S. Lucien Goldmann ou a dialética da totalidade. São Paulo:

Boitempo Editorial, 2008.

OLIVEIRA, Carlos. Obras de Carlos de Oliveira. Lisboa: Editorial Caminho, 1992.

PEPETELA. Mayombe. São Paulo: Editora Ática, 1982.

SAID, Edward W. Orientalismo: o Oriente como invenção do Ocidente. Trad.: Tomás Rosa Bueno. São Paulo: Companhia das Letras, 1990. 